\title{
Orientation-Dependent Oxygen Evolution on RuO2 without Lattice Exchange
}

Stoerzinger, Kelsey A. ; Diaz-Morales, Oscar ; Kolb, Manuel ; Rao, Reshma R. ; Frydendal, Rasmus; Qiao, Liang ; Wang, Xiao Renshaw ; Halck, Niels Bendtsen; Rossmeisl, Jan; Hansen, Heine Anton Total number of authors:

14

Published in:

ACS Energy Letters

Link to article, DOI:

10.1021/acsenergylett.7b00135

Publication date:

2017

Document Version

Peer reviewed version

Link back to DTU Orbit

Citation (APA):

Stoerzinger, K. A., Diaz-Morales, O., Kolb, M., Rao, R. R., Frydendal, R., Qiao, L., Wang, X. R., Halck, N. B., Rossmeisl, J., Hansen, H. A., Vegge, T., E. L. Stephens, I., Koper, M. T. M., \& Shao-Horn, Y. (2017).

Orientation-Dependent Oxygen Evolution on RuO without Lattice Exchange. ACS Energy Letters, 2(4), 876881. https://doi.org/10.1021/acsenergylett.7b00135

\section{General rights}

Copyright and moral rights for the publications made accessible in the public portal are retained by the authors and/or other copyright owners and it is a condition of accessing publications that users recognise and abide by the legal requirements associated with these rights.

- Users may download and print one copy of any publication from the public portal for the purpose of private study or research.

- You may not further distribute the material or use it for any profit-making activity or commercial gain

- You may freely distribute the URL identifying the publication in the public portal 


\title{
Orientation-Dependent Oxygen Evolution on $\mathrm{RuO}_{2}$ without Lattice Exchange
}

\author{
Kelsey A. Stoerzinger, ${ }^{1, \#, \dagger, *}$ Oscar Diaz-Morales, ${ }^{2, \#, 4}$ Manuel Kolb, ${ }^{3}$ Reshma R. Rao, ${ }^{3}$ Rasmus

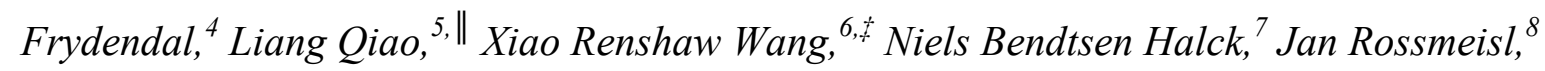 \\ Heine A. Hansen, ${ }^{7}$ Tejs Vegge, ${ }^{7}$ Ifan E. L. Stephens, ${ }^{3,4}$ Marc T. M. Koper, ${ }^{2}$ Yang Shao-Horn ${ }^{1,3,6, *}$ \\ ${ }^{1}$ Department of Materials Science and Engineering, Massachusetts Institute of Technology, \\ Cambridge, Massachusetts 02139, United States \\ ${ }^{2}$ Leiden Institute of Chemistry, Leiden University, PO Box 9502, 2300 RA, Leiden, The \\ Netherlands \\ ${ }^{3}$ Department of Mechanical Engineering, Massachusetts Institute of Technology, Cambridge, \\ Massachusetts 02139, United States \\ ${ }^{4}$ Center for Individual Nanoparticle Functionality, Department of Physics, Technical University \\ of Denmark, 2800 Kgs. Lyngby, Denmark \\ ${ }^{5}$ Center for Nanophase Materials Sciences, Oak Ridge National Laboratory, 1 Bethel Valley \\ Road, Oak Ridge, TN, 37831, United States \\ ${ }^{6}$ Research Laboratory of Electronics, Massachusetts Institute of Technology, Cambridge, \\ Massachusetts 02139, United States
}


${ }^{7}$ Department of Energy Conversion and Storage, Technical University of Denmark, 2800 Kgs. Lyngby, Denmark

${ }^{8}$ Department of Chemistry, University of Copenhagen, Universitetsparken 5, 2100 Copenhagen, Denmark

${ }^{\dagger}$ Current address: Physical and Computational Sciences Directorate, Pacific Northwest National Laboratory, Richland Washington 99354, United States

${ }^{\Delta}$ Current address: Department of Physics, AlbaNova University Center, Stockholm University, S-10691 Stockholm, Sweden

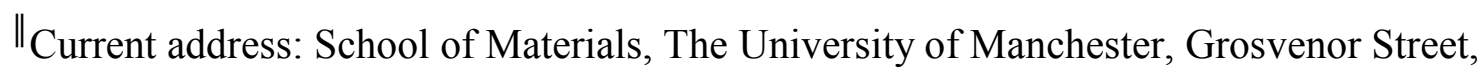
Manchester, M13 9PL, UK

${ }^{\ddagger}$ Current address: School of Physical and Mathematical Sciences \& School of Electrical and Electronic Engineering, Nanyang Technological University, Singapore 637371

${ }^{\#}$ Equal contributors

\title{
Corresponding Author
}

*kelsey.stoerzinger@pnnl.gov; shaohorn@mit.edu

\begin{abstract}
RuO}_{2}$ catalysts exhibit record activities towards the oxygen evolution reaction (OER), which is crucial to enable efficient and sustainable energy storage. Here we examine the $\mathrm{RuO}_{2}$ OER kinetics on rutile (110), (100), (101), and (111) orientations, finding (100) the most active. We assess the potential involvement of lattice oxygen in the OER mechanism with online
\end{abstract}


electrochemical mass spectrometry, which showed no evidence of oxygen exchange on these oriented facets in acidic or basic electrolytes. Similar results were obtained for polyoriented $\mathrm{RuO}_{2}$ films and particles, in contrast to previous work, suggesting lattice oxygen is not exchanged in catalyzing OER on crystalline $\mathrm{RuO}_{2}$ surfaces. This hypothesis is supported by the correlation of activity with the number of active Ru-sites calculated by DFT, where more active facets bind oxygen more weakly. This new understanding of the active sites provides a design strategy to enhance the OER activity of $\mathrm{RuO}_{2}$ nanoparticles by facet engineering.

\section{TOC GRAPHIC}

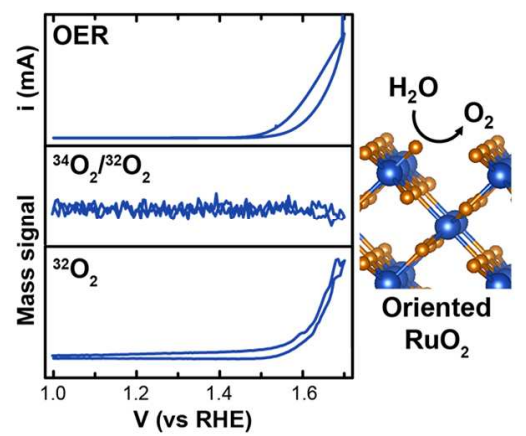

Efficient catalysis of the oxygen evolution reaction (OER) is critical for the storage of renewable energy by hydrogen evolution or $\mathrm{CO}_{2}$ reduction. ${ }^{1-3}$ The rutile phase of ruthenium dioxide has remarkable OER activity, serving as a benchmark material for the reaction in either acidic $^{4}$ or alkaline media. ${ }^{5-6}$ Despite notable experimental and theoretical work in $\mathrm{RuO}_{2}$ catalyzed OER, ${ }^{7-8}$ with catalysts ranging from nanoparticles ${ }^{5,} 9$ to single crystals, ${ }^{10}$ the mechanism remains unclear. ${ }^{11}$ Some ambiguities exist about the coordination of ruthenium in $\mathrm{RuO}_{2}$ active sites and about the role of lattice oxygen in OER. Regarding the Ru active sites, the different coordination of surface $\mathrm{Ru}$ atoms on each crystallographic facet bears ramifications on their redox potential, ${ }^{12}$ in turn affecting the activation energy of charge-transfer steps in the OER. 
With regard to the lattice oxygen involvement in OER, design parameters instead focus on more bulk-like descriptors such as the oxygen $2 p$-band energy level. ${ }^{13}$

Four types of mechanisms have been suggested in the literature for the $\mathrm{OER}$ in $\mathrm{RuO}_{2}($ Figure $\mathrm{S} 1$ ): (1) four concerted proton-electron transfers occurring on a single (undercoordinated $\mathrm{Ru}$ ) site, $^{7}$ supported by density functional theory (DFT) calculations, (2) a sequence of two electrochemical steps followed by two chemical steps between neighboring $\mathrm{Ru}$ sites, ${ }^{14}$ due to differences in Tafel relations with tortuosity, (3) decomposition of high valence Ru oxides, ${ }^{15-16}$ based on thermodynamic parameters, and (4) a mechanism involving the exchange of catalyst's lattice oxygen during the OER from isotopic labeling studies. ${ }^{17-18}$ Understanding the nature of the active sites and the involvement of lattice oxygen in the OER is fundamental to reconcile the existing OER mechanism or propose a new one, and this is the key in developing appropriate activity descriptors and parameters for rational design of $\mathrm{RuO}_{2}$ catalysts.

In this work, we examine the activities and the degree of oxygen exchange on four crystallographic orientations of $\mathrm{RuO}_{2}$ to probe the nature of active sites for OER, employing ${ }^{18} \mathrm{O}$ labelling and OLEMS. The results will be discussed in the light of our recent work showing that the OER activity of rutile $\mathrm{RuO}_{2}(110)$ is lower than that of $\mathrm{RuO}_{2}(100),{ }^{6}$ along with the historic studies reporting oxygen exchange during OER on $\mathrm{RuO}_{2}$ in acidic media. ${ }^{17-18}$ We report that for the oriented surfaces of (100), (110), (101), and (111), oxygen exchange was not observed to coincide with the OER, regardless of orientation in either acid or base. Moreover, dense sputterdeposited rutile films (annealed at $300{ }^{\circ} \mathrm{C}$ ) and crystalline $\mathrm{RuO}_{2}$ nanoparticles of $\sim 50 \mathrm{~nm}$ in size did not exhibit notable exchange. The lack of oxygen exchange is supported by DFT results probing the adsorption of oxygen on different orientations, identifying the number of active $\mathrm{Ru}$ sites on the four surfaces, which scales with the experimental activity. These findings provide a 
design strategy to enhance the OER activity of $\mathrm{RuO}_{2}$ nanoparticles through facet engineering for practical use.

Rutile films of (100), (110), (101), and (111) orientation were grown by pulsed laser deposition (PLD), as reported previously ${ }^{6}$ and detailed in the Experimental Methods (Supplemental Information). The orientation was confirmed by X-ray diffraction (Figure S2). All films are comparably smooth by atomic force microscopy (AFM, Figure S3), with low rootmean-square roughness $\sim 1 \mathrm{~nm}$. Polyoriented films were grown by reactive sputter deposition on Si (Figure S4), as reported previously, ${ }^{19}$ and nanoparticles (Figure S5, S6) were purchased commercially.

We first establish the uniqueness of film orientations and their dense structure by considering the surface redox behavior and cathodic pseudocapacitive charge ( $q^{*}$ cathodic $)$ measured in Arsaturated electrolyte. ${ }^{20-21}$ The capacitive features differ notably for each orientation in $0.1 \mathrm{M}$ $\mathrm{KOH}$ (Figure 1A, see Figure $\mathrm{S} 7$ for $0.1 \mathrm{M} \mathrm{HClO}_{4}$ ), and scale with the density of undercoordinated Ru-bonds on each projected ideal surface, as shown in Table S1 (Figure 1B, Figure S8). As $q^{*}$ cathodic has been found to increase directly with surface area, ${ }^{14}$ its agreement with that expected from a flat surface leads us to conclude that the oriented thin films are not only smooth but also dense, lacking the porosity and corresponding defects typically associated with polycrystalline films or nanoparticles. 

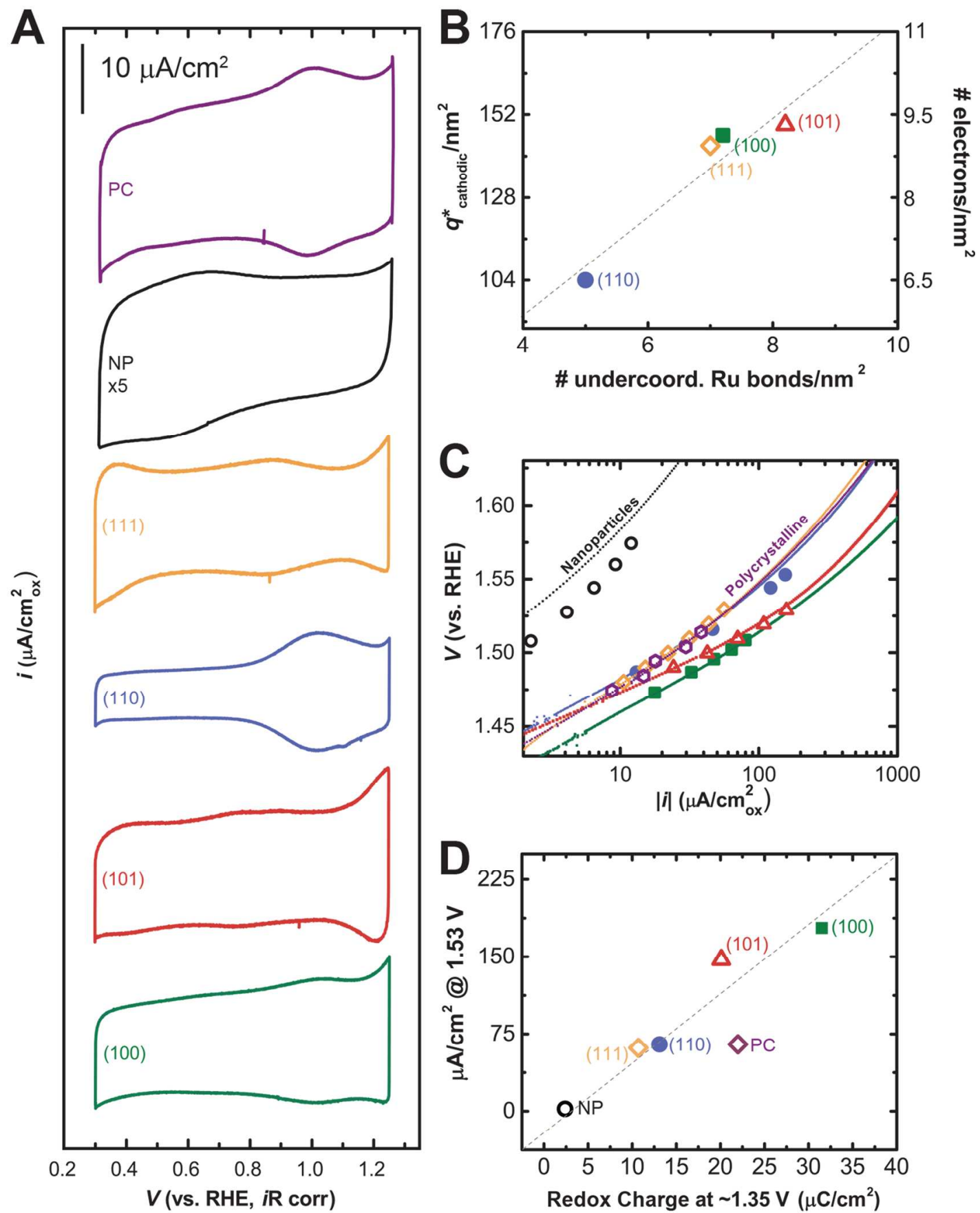

Figure 1. (A) Cyclic voltammetry of $\mathrm{RuO}_{2}$ of noted orientation in Ar-saturated $0.1 \mathrm{M} \mathrm{KOH}$ at 50 $\mathrm{mV} / \mathrm{s}$ in the voltage window from 0.3 to $1.25 \mathrm{~V}$ versus RHE. The cathodic charge in the voltammogram was used to calculate the charge density, $q^{*}$ cathodic, as suggested by previous work. $^{21}$ The current density from nanoparticles (NP) is multiplied by 5 to show on the same scale. (B) $q^{*}$ cathodic (and corresponding number of electrons transferred) versus the number of 
undercoordinated Ru bonds at the surface counted from the noted crystal facets (Figure S8, Table $\mathrm{S} 1)$. The dashed line guides the eye for 1:1 correlation. (C) Tafel plot of OER activity in $\mathrm{O}_{2}$ saturated $0.1 \mathrm{M} \mathrm{KOH}$, measured by cyclic voltammetry at $10 \mathrm{mV} / \mathrm{s}$ (averaged forward and back, line) and potentiostatic measurements (constant applied voltage, points). (D) OER activity at $1.53 \mathrm{~V}$ vs. RHE corresponds to the integrated charge from the Ru redox located at $\sim 1.35 \mathrm{~V}$ vs. RHE preceding the onset of OER (Figure S10). (100) and (110) data adapted from Ref. 6.

The specific OER activities (normalized by geometrical surface area) of the different crystal orientations differ notably, with (100) being the most active in $0.1 \mathrm{M} \mathrm{KOH}$. The OER activities measured by cyclic voltammetry $(\mathrm{CV})$ and potentiostatic measurements (see Experimental Methods) provide comparable results (Figure 1C). AFM measurements after cycling show negligible changes in surface roughness (Figure S9), pointing to material stability over the $\sim 1$ hour of measurements. The OER activity scales with the integrated $\mathrm{Ru}$ redox peak at $\sim 1.35 \mathrm{~V}$ vs. RHE (Figure S10), ${ }^{6}$ preceding the onset of OER, for all orientations.

We next assess the potential involvement of lattice oxygen by OLEMS measurements. ${ }^{22}$ The films were held potentiostatically at OER potentials $(1.7 \mathrm{~V})$ in $0.1 \mathrm{M} \mathrm{KOH}$ or galvanostatically at low current densities in $0.1 \mathrm{M} \mathrm{H}_{2} \mathrm{SO}_{4}$ or $\mathrm{KOH}$ (Figure $\mathrm{S} 11$ ), where the electrolyte was prepared with ${ }^{18} \mathrm{O}$-labeled water. After rinsing and replacing the electrolyte with that prepared from DI water $\left({ }^{16} \mathrm{O}\right)$, the masses of evolved oxygen were measured during OER.

We begin by considering the most stable (110) facet in $0.1 \mathrm{M} \mathrm{KOH}$, on which numerous DFT calculations have considered a reaction mechanism involving adsorption on a single undercoordinated Ru-site, ${ }^{7}$ not involving lattice oxygen. We first performed OER at $10 \mu \mathrm{A}$ $\left(\sim 1.55 \mathrm{~V}\right.$ vs. RHE) in $\mathrm{H}_{2}{ }^{18} \mathrm{O}-0.1 \mathrm{M} \mathrm{KOH}$, where the oxide would become 'labeled' by ${ }^{18} \mathrm{O}$ if lattice oxygen is involved (Figure S11). The electrolyte was then thoroughly rinsed and replaced 
with $\mathrm{H}_{2}{ }^{16} \mathrm{O}-0.1 \mathrm{M} \mathrm{KOH}$, and OER again measured. In concert with the measured oxidation current, notable ${ }^{32} \mathrm{O}_{2}\left({ }^{16} \mathrm{O}+{ }^{16} \mathrm{O}\right)$ gas evolution was observed (Figure 2A), and negligible formation of ${ }^{34} \mathrm{O}_{2}\left({ }^{18} \mathrm{O}+{ }^{16} \mathrm{O}\right)$ and of ${ }^{36} \mathrm{O}_{2}\left({ }^{18} \mathrm{O}+{ }^{18} \mathrm{O}\right)$ was detected, where the ratio of ${ }^{34} \mathrm{O}_{2}$ to ${ }^{32} \mathrm{O}_{2}$ detected as a function of applied potential is comparable to that of the natural enrichment of DI water in ${ }^{16} \mathrm{O}$ and ${ }^{18} \mathrm{O}$ isotopes, within experimental uncertainty (Figure 2A bottom panel, Figure S12). Comparable results were obtained by potentiostatic holding at $1.7 \mathrm{~V}$ in $\mathrm{H}_{2}{ }^{18} \mathrm{O}-0.1 \mathrm{M}$ $\mathrm{KOH}$ (Figure S12). This observation is in contrast to the detection of oxygen exchange on a polycrystalline gold disk polarized to $2 \mathrm{~V}$ (gold's onset for OER) ${ }^{23}$ and from oxide powders ${ }^{13}$ of comparable surface area to the $\mathrm{RuO}_{2}$ electrodes using an identical setup.
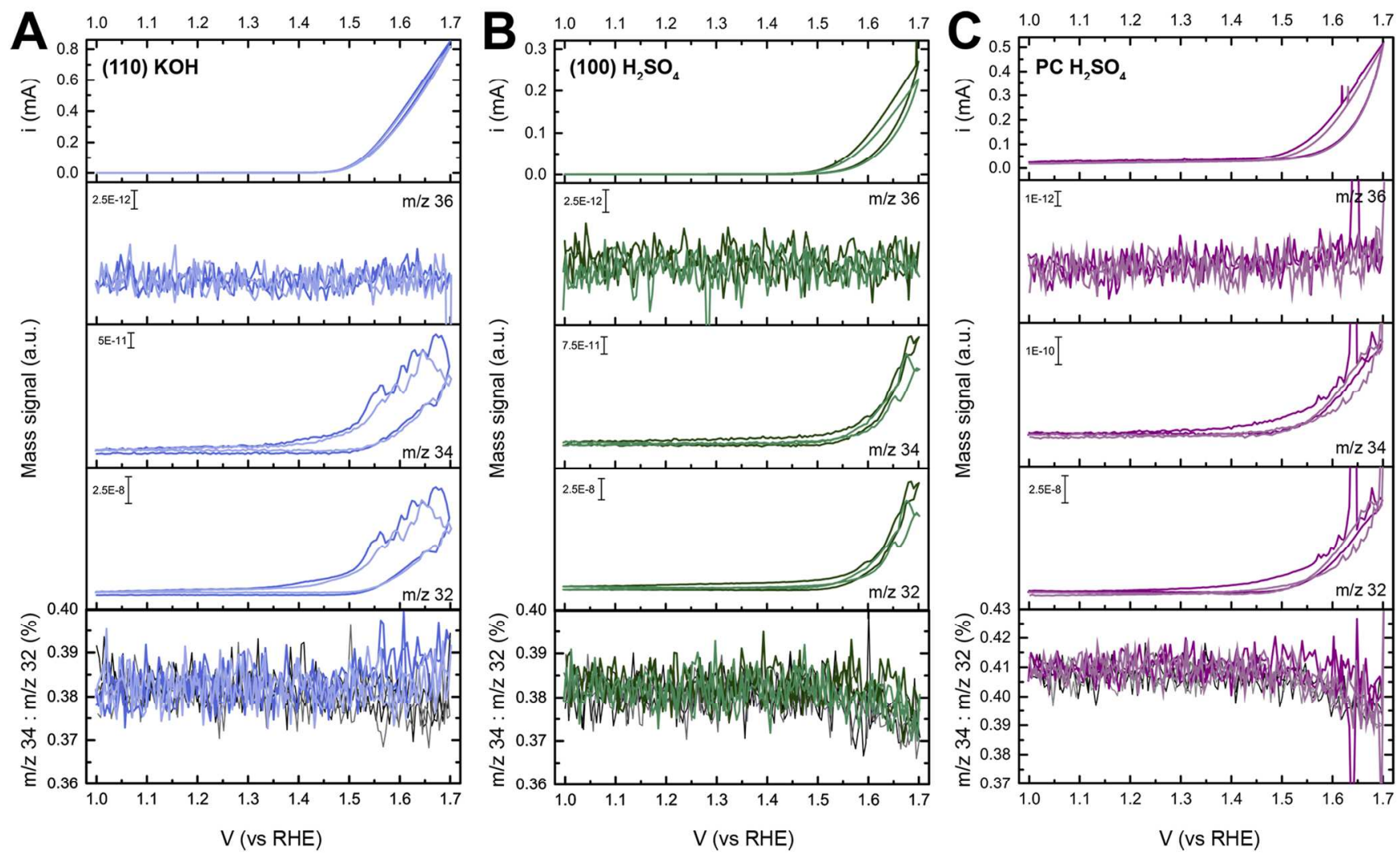

Figure 2. Online electrochemical mass spectrometry (OLEMS) measurements at $2 \mathrm{mV} / \mathrm{s}$ (see Experimental Methods for details). Shown is the current as a function of applied voltage, along with the mass signals collected in parallel for ${ }^{36} \mathrm{O}_{2},{ }^{34} \mathrm{O}_{2}\left({ }^{18} \mathrm{O}^{16} \mathrm{O}\right)$, and ${ }^{32} \mathrm{O}_{2}$ for a film 
galvanostatically polarized in $\mathrm{H}_{2}{ }^{18} \mathrm{O}$ to potentially 'label' it, measured in $\mathrm{H}_{2}{ }^{16} \mathrm{O}$ electrolyte (dark color first sweep, light color second). The ratio of the mass 34 to mass 32 signal, which is independent of applied potential and overtop the same ratio measured after aggressive polarization to remove any exchanged oxygen (black/gray sweeps), indicates any ${ }^{34} \mathrm{O}_{2}$ arises from background ${ }^{18} \mathrm{O}$. (A) (110)- $\mathrm{RuO}_{2}$ in $0.1 \mathrm{M} \mathrm{KOH}$, (B) (100)- $\mathrm{RuO}_{2}$ in $0.1 \mathrm{M} \mathrm{H}_{2} \mathrm{SO}_{4}$, and (C) sputter-deposited polyoriented polycrystalline (PC) $\mathrm{RuO}_{2}$ in $0.1 \mathrm{M} \mathrm{H}_{2} \mathrm{SO}_{4}$.

No involvement of lattice oxygen exchange was detected during OER in $0.1 \mathrm{M} \mathrm{KOH}$ on more active (100) (Figure S13-14) or (101) (Figure S15-16), or more undercoordinated (111) (Figure S17-18) by either galvanostatic or potentiostatic labeling approaches. Moreover, we performed OLEMS in $0.1 \mathrm{M} \mathrm{H}_{2} \mathrm{SO}_{4}$, where these oriented films also do not exhibit oxygen exchange during OER (Figures 2B, S14, S16, S18). The lack of oxygen exchange on these oriented $\mathrm{RuO}_{2}$ films in either basic or acidic environments in this study is in contrast to the observation of lattice involvement for polycrystalline $\mathrm{RuO}_{2} \mathrm{RF}$ sputtered onto a membrane ${ }^{17}$ and nanocrystalline particles; ${ }^{18}$ the discrepancy is not understood. Here, we postulate that the involvement of oxygen exchange in OER is not associated with rutile $\mathrm{RuO}_{2}$, but potentially rather with $\mathrm{RuO}_{2}$-based amorphous or nanocrystalline phases with undercoordinated edge-sites presented in these previous studies. ${ }^{17-18}$ This hypothesis is supported by lack of oxygen exchange (Figure $2 \mathrm{C}$, Figure S19) during OER on polyoriented, polycrystalline $\mathrm{RuO}_{2}$ (prepared by reactive sputter deposition at $300{ }^{\circ} \mathrm{C}$ in 3 mTorr of 5:2 $\mathrm{Ar}_{2} \mathrm{O}_{2}$ ) in acid, ${ }^{19}$ having comparable charge associated with the peak at $\sim 1.35 \mathrm{~V}$ vs. RHE (Figure 1D) and OER activity (Figure 1D) comparable to oriented surfaces. Moreover, no oxygen exchange was detected on rutile $\mathrm{RuO}_{2}$ nanoparticles (Figure S20) of $\sim 50 \mathrm{~nm}$ in size (Figure S6), having a slightly lower activity and a lower charge 
associated with the redox peak at $\sim 1.35 \mathrm{~V}$ (Figure 1D) normalized to Brunauer-Emmett-Teller (BET) surface area.

In the context of previous work, these new findings suggest that lattice oxygen is involved in a secondary mechanism only in less-crystalline ruthenium oxide or at low-coordinated nanoparticle surfaces with large surface area to bulk ratios. This difference suggests the importance of defect sites or other variations in surface crystallinity influenced by synthesis method. ${ }^{24}$ Furthermore, the geometry of the RF-sputtered $\mathrm{RuO}_{2}$ electrode in previous studies ${ }^{17}$ is likely characterized by a degree of surface roughness and porosity due to its deposition on a polymer membrane, which can potentially trap isotopically labelled water during the exchange experiment, convoluting results. The exchange of lattice oxygen may be possible in lowcoordinated surface sites of less-crystalline but yet electrochemically active catalysts having nominal " $\mathrm{RuO}_{2}$ " stoichiometry, with such a difference in reaction mechanism likely bearing ramifications on stability as well. Fortunately, such exchange is not necessary to achieve high catalytic activity in oriented films.

To help better quantify the number of active sites on the surface, we performed DFT calculations (see Experimental Methods) on the four experimentally studied $\mathrm{RuO}_{2}$ facets. We assume that these surfaces do not undergo reconstruction; thus the surface orientation is commensurate with that of the overall film. To this end, we calculated the oxygen adsorption energies for sites linked to the different types of Ru atoms on the surface. We observe the possibility to adsorb in various positions onto the different adsorption sites with varied energies. However, we find a common trend in the onset of the transition of the stoichiometric surface to the oxidized surface. We observe the Gibbs free energies per $\mathrm{O}$ atom for the oxygen adsorption on the Ru-sites labeled as 'active' undercoordinated sites to be $1.90 \mathrm{eV}$ on the (100) surface, 2.01 
$\mathrm{eV}$ for the (101) surface, $1.77 \mathrm{eV}$ for the active site on the (110) surface and $1.59 \mathrm{eV}$ for the (111) surface. Here, the adsorption energy is defined as the last, sequential addition of oxygen, which stabilizes the surface with the highest oxygen coverage at the pre-OER potentials under investigation here. Greater Gibbs free energies of adsorption correspond to higher potentials for the $\mathrm{Ru}$ redox peak preceding the onset of OER (Figure S10), and higher OER activity (Figure 3). The relative stability of the surfaces are found to be in good agreement with previous computational work on $\mathrm{RuO}_{2}$ surfaces and nanoparticles, ${ }^{12,25}$ but with the interesting addition of a new oxygen rich termination on the open (111) surface, where the active Ru-site is tetrahedrally coordinated to oxygen, see Figure 3D and S21.

The additional oxygen atoms that cause the transitions with similar adsorption energies as the active coordinatively undersaturated (CUS) site on the (110) surface are shown in Figures 3A-D. For the (100) (Figure 3A) and (101) (Figure 3B) facets, we find that all surface Ru atoms are active (i.e. have similar oxygen adsorption energy), while for the (110) surface (Figure 3C) only the CUS sites are active and for the (111) facet (Figure 3D) only every third surface Ru atom is active. From this, we observe a trend for the density of the undercoordinated Ru sites, which is shown in Figure 3E. 


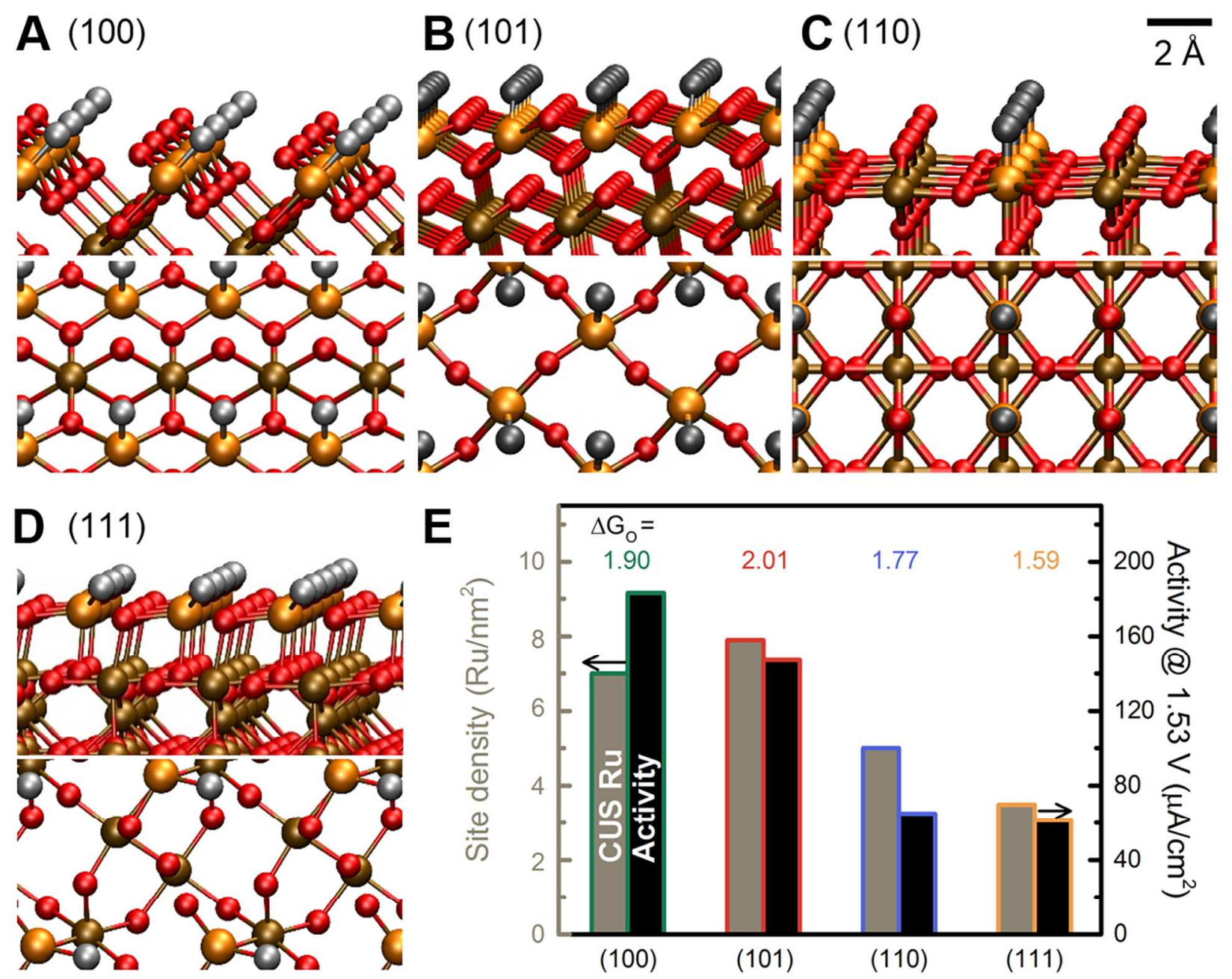

Figure 3. (A-D) $\mathrm{RuO}_{2}$ surfaces viewed from the side (top) and from above (bottom), where Oatoms are in red, inactive $\mathrm{Ru}$ atoms are in brown, and active undercoordinated sites are marked with a larger sphere in gold with silver atoms marking the location of the oxygen atom adsorbed on the active site. All images are on the same scale. (E) The OER activity at $1.53 \mathrm{~V}$ vs. RHE (right axis, black) scales with the number of active undercoordinated sites per area from DFT calculations (left axis, gray) for the four studied $\mathrm{RuO}_{2}$ orientations. A weaker Gibbs free energies per $\mathrm{O}$ atom $\left(\Delta \mathrm{G}_{\mathrm{O}}\right.$, in $\left.\mathrm{eV}\right)$ also corresponds to higher activity.

Given the experimental observation that high OER activity correlates with greater Ru redox preceding OER (Figure 1D), we hypothesize that these undercoordinated Ru are active for OER. 
Indeed, the OER activity correlates not with the overall $\mathrm{Ru}$ density on each facet, but with the DFT-calculated density of undercoordinated Ru (Figure 3E), where the most active (100) and (101) surfaces have the highest density of undercoordinated $\mathrm{Ru}$ and also bind $\mathrm{O}$ the weakest. This clearly indicates the involvement of active $\mathrm{Ru}$ sites in the reaction mechanism, which involves their ability to be oxidized and reduced. Comparison of the charge associated with the redox feature proceeding the onset of OER (Figure 1D, S10) with the density of active Ru atoms on each orientation indicates that the (100) surface also has the highest utilization of surface $\mathrm{Ru}$ atoms (Table S2). Our findings, where $\mathrm{RuO}_{2}$ does not exhibit oxygen exchange and activity trends with the number of active $\mathrm{Ru}$ sites and their $\mathrm{O}$ binding strength, supports previously proposed mechanisms involving an undercoordinated active $\mathrm{Ru}$ site, ${ }^{7}$ however we cannot assess the role of lateral interactions ${ }^{24,26}$ or active valence state at this time. Ongoing work concerns the balance between proton-electron transfer and $\mathrm{pH}$ effects in the reaction mechanism. The correlation of activity with metal sites and not the exposed lattice oxygen density on different crystallographic facets suggests that active, stable catalysts should maximize the exposure of (100) and (101) facets in engineered nanoparticles.

In this study, we report that rutile $\mathrm{RuO}_{2}$ (100) and (101) surfaces are more active for the oxygen evolution reaction (OER) than their (110) and (111) counterparts in alkaline solution, where activity scales with $\mathrm{Ru}$ oxidation. Oxygen isotope studies employing OLEMS do not evidence appreciable oxygen exchange during the OER on well-crystallized, oriented thin films in either acidic or basic media. Furthermore, measurements of dense polycrystalline films and commercial nanoparticles also suggest no oxygen exchange, in contrast to previous studies. ${ }^{17-18}$ DFT calculations suggest undercoordinated $\mathrm{Ru}$ atoms on crystallized facets are active sites for the OER, the density of which correlates with activity on the four $\mathrm{RuO}_{2}$ orientations. Our work 
highlights the importance of understanding the surface atomic structure of oxides to tune catalytic activity and possibly the reaction mechanism, and such work can open up new design strategies to engineer nanoparticles with enhanced OER activity.

Supporting Information. Experimental methods, additional characterization, electrochemical testing, and OLEMS. The following files are available free of charge.

Supporting information (PDF)

\section{AUTHOR INFORMATION}

\section{Notes}

The authors declare no competing financial interests.

\section{ACKNOWLEDGEMENT}

We thank Binghong Han for TEM characterization of $\mathrm{RuO}_{2}$ nanoparticles. IELS gratefully acknowledges the MIT award of the Peabody Visiting Associate Professorship. The film growth and structural characterization at ORNL were supported by the U.S. Department of Energy, Office of Science, Basic Energy Sciences, Materials Sciences and Engineering Division. This work is supported in part by the Skoltech-MIT Center for Electrochemical Energy, and the Cooperative Agreement between the Masdar Institute, Abu Dhabi, UAE and MIT (02/MI/MIT/CP/11/07633/GEN/G/00). This work is also supported in part by the Netherlands Organization for Scientific Research (NWO) within the research programme of BioSolar Cells, co-financed by the Dutch Ministry of Economic Affairs, Agriculture and Innovation, as well as The Velux Foundations through the research center V-Sustain (grant 9455). 


\section{REFERENCES}

(1) Trasatti, S. Electrocatalysis by Oxides - Attempt at a Unifying Approach. J. Electroanal. Chem. Interfacial Electrochem. 1980, 111, 125-131.

(2) Duan, L.; Bozoglian, F.; Mandal, S.; Stewart, B.; Privalov, T.; Llobet, A.; Sun, L. A Molecular Ruthenium Catalyst with Water-oxidation Activity Comparable to that of Photosystem II. Nat. Chem. 2012, 4, 418-423.

(3) Greeley, J.; Markovic, N. M. The road from animal electricity to green energy: combining experiment and theory in electrocatalysis. Energy Environ. Sci 2012, 5, 9246-9256.

(4) Trasatti, S. Electrocatalysis in the Anodic Evolution of Oxygen and Chlorine. Electrochim. Acta 1984, 29, 1503-1512.

(5) Lee, Y.; Suntivich, J.; May, K. J.; Perry, E. E.; Shao-Horn, Y. Synthesis and Activities of Rutile IrO and $\mathrm{RuO}_{2}$ Nanoparticles for Oxygen Evolution in Acid and Alkaline Solutions. J. Phys. Chem. Lett. 2012, 3, 399-404.

(6) Stoerzinger, K. A.; Qiao, L.; Biegalski, M. D.; Shao-Horn, Y. Orientation-Dependent Oxygen Evolution Activities of Rutile $\mathrm{IrO}_{2}$ and $\mathrm{RuO}_{2}$. J. Phys. Chem. Lett. 2014, 5, 1636-1641.

(7) Rossmeisl, J.; Qu, Z. W.; Zhu, H.; Kroes, G. J.; Nørskov, J. K. Electrolysis of Water on Oxide Surfaces. J. Electroanal. Chem. 2007, 607, 83-89.

(8) Man, I. C.; Su, H.-Y.; Calle-Vallejo, F.; Hansen, H. A.; Martínez, J. I.; Inoglu, N. G.; Kitchin, J.; Jaramillo, T. F.; Nørskov, J. K.; Rossmeisl, J. Universality in Oxygen Evolution Electrocatalysis on Oxide Surfaces. ChemCatChem 2011, 3, 1159-1165.

(9) Nguyen, T. D.; Scherer, G. G.; Xu, Z. J. A Facile Synthesis of Size-Controllable $\mathrm{IrO}_{2}$ and $\mathrm{RuO}_{2}$ Nanoparticles for the Oxygen Evolution Reaction. Electrocatalysis 2016, 7, 420-427.

(10) Castelli, P.; Trasatti, S.; Pollak, F. H.; O'Grady, W. E. Single Crystals as Model Electrocatalysts: Oxygen Evolution on $\mathrm{RuO}_{2}$ (110). J. Electroanal. Chem. Interfacial Electrochem. 1986, 210, 189194.

(11) Reier, T.; Nong, H. N.; Teschner, D.; Schlögl, R.; Strasser, P. Electrocatalytic Oxygen Evolution Reaction in Acidic Environments - Reaction Mechanisms and Catalysts. Adv. Energy Mater. 2017, 7, 1601275.

(12) Wang, T.; Jelic, J.; Rosenthal, D.; Reuter, K. Exploring Pretreatment-Morphology Relationships: $\mathrm{Ab}$ Initio Wulff Construction for $\mathrm{RuO}_{2}$ Nanoparticles under Oxidising Conditions. ChemCatChem 2013, 5, 3398-3403.

(13) Grimaud, A.; Diaz-Morales, O.; Han, B.; Hong, W. T.; Lee, Y.-L.; Giordano, L.; Stoerzinger, K. A.; Koper, M. T. M.; Shao-Horn, Y. Activating lattice oxygen redox reactions in metal oxides to catalyze oxygen evolution. Nat. Chem. 2016, DOI: 10.1038/nchem.2695.

(14) Lodi, G.; Sivieri, E.; Battisti, A.; Trasatti, S. Ruthenium dioxide-based film electrodes. J. Appl. Electrochem. 1978, 8, 135-143.

(15) Lyons, M. E. G.; Burke, L. D. Mechanism of Oxygen Reactions at Porous Oxide Electrodes. Part 1.Oxygen Evolution at $\mathrm{RuO}_{2}$ and $\mathrm{Ru}_{x} \mathrm{Sn}_{1-\mathrm{x}} \mathrm{O}_{2}$ Electrodes in Alkaline Solution Under Vigorous Electrolysis Conditions. J. Chem. Soc., Faraday Trans. 1 1987, 83, 299-321.

(16) Lyons, M. E. G.; Floquet, S. Mechanism of Oxygen Reactions at Porous Oxide Electrodes. Part 2Oxygen Evolution at $\mathrm{RuO}_{2}, \mathrm{IrO}_{2}$ and $\mathrm{Ir}_{\mathrm{x}} \mathrm{Ru}_{1-\mathrm{x}} \mathrm{O}_{2}$ Electrodes in Aqueous Acid and Alkaline Solution. Phys. Chem. Chem. Phys. 2011, 13, 5314-5335. 
(17) Wohlfahrt-Mehrens, M.; Heitbaum, J. Oxygen evolution on $\mathrm{Ru}$ and $\mathrm{RuO}_{2}$ electrodes studied using isotope labelling and on-line mass spectrometry. J. Electroanal. Chem. Interfacial Electrochem. 1987, 237, 251-260.

(18) Macounova, K.; Makarova, M.; Krtil, P. Oxygen evolution on nanocrystalline $\mathrm{RuO}_{2}$ and $\mathrm{Ru}_{0.9} \mathrm{Ni}_{0.1} \mathrm{O}_{2-\delta}$ electrodes - DEMS approach to reaction mechanism determination. Electrochem. Commun. 2009, 11, 1865-1868.

(19) Frydendal, R.; Paoli, E. A.; Knudsen, B. P.; Wickman, B.; Malacrida, P.; Stephens, I. E. L.; Chorkendorff, I. Benchmarking the Stability of Oxygen Evolution Reaction Catalysts: The Importance of Monitoring Mass Losses. ChemElectroChem 2014, 1, 2075-2081.

(20) Guerrini, E.; Chen, H.; Trasatti, S. Oxygen Evolution on Aged $\mathrm{IrO}_{x} / \mathrm{Ti}$ Electrodes in Alkaline Solutions. J. Solid State Electrochem. 2007, 11, 939-945.

(21) Burke, L. D.; Murphy, O. J. Cyclic Voltammetry as a Technique for Determining the Surface Area of $\mathrm{RuO}_{2}$ Electrodes. J. Electroanal. Chem. Interfacial Electrochem. 1979, 96, 19-27.

(22) Wonders, A. H.; Housmans, T. H. M.; Rosca, V.; Koper, M. T. M. On-line mass spectrometry system for measurements at single-crystal electrodes in hanging meniscus configuration. J. Appl. Electrochem. 2006, 36, 1215-1221.

(23) Diaz-Morales, O.; Calle-Vallejo, F.; de Munck, C.; Koper, M. T. M. Electrochemical water splitting by gold: evidence for an oxide decomposition mechanism. Chem. Sci. 2013, 4, 2334-2343.

(24) Exner, K. S.; Anton, J.; Jacob, T.; Over, H. Ligand Effects and Their Impact on Electrocatalytic Processes Exemplified with the Oxygen Evolution Reaction (OER) on $\mathrm{RuO}_{2}(110)$. ChemElectroChem 2015, 2, 707-713.

(25) Wang, T.; Reuter, K. Structure sensitivity in oxide catalysis: First-principles kinetic Monte Carlo simulations for CO oxidation at RuO2(111). J. Chem. Phys. 2015, 143, 204702.

(26) Halck, N. B.; Petrykin, V.; Krtil, P.; Rossmeisl, J. Beyond the volcano limitations in electrocatalysis - oxygen evolution reaction. Phys. Chem. Chem. Phys. 2014, 16, 13682-13688. 

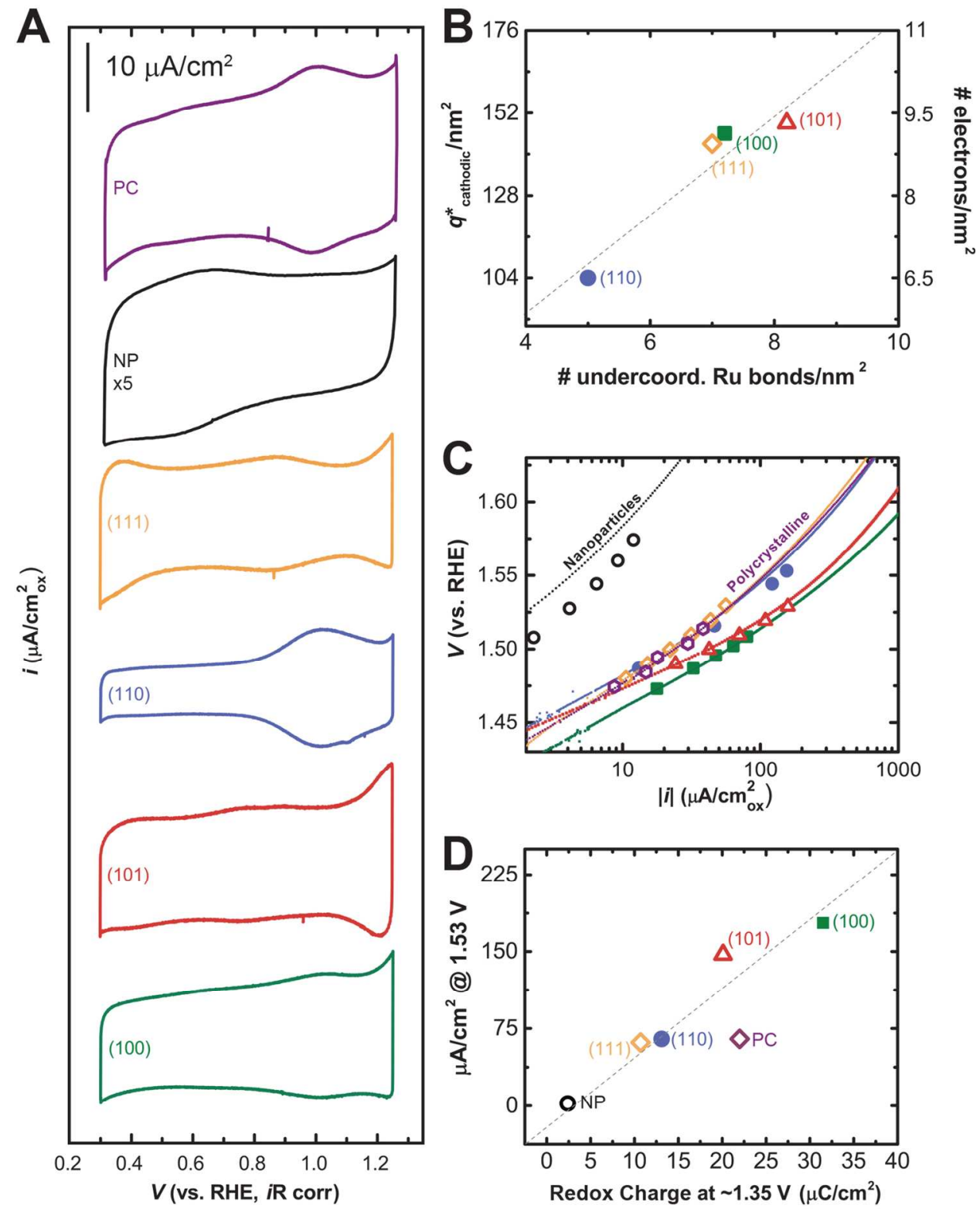

Figure 1. (A) Cyclic voltammetry of $\mathrm{RuO}_{2}$ of noted orientation in Ar-saturated $0.1 \mathrm{M} \mathrm{KOH}$ at $50 \mathrm{mV} / \mathrm{s}$ in the voltage window from 0.3 to $1.25 \mathrm{~V}$ versus RHE. The cathodic charge in the voltammogram was used to calculate the charge density, $\mathrm{q}^{*}$ cathodic, as suggested by previous work. ${ }^{21}$ The current density from nanoparticles (NP) is multiplied by 5 to show on the same scale. (B) $\mathrm{q}^{*}$ cathodic (and corresponding number of electrons transferred) versus the number of undercoordinated Ru bonds at the surface counted from the noted crystal facets (Figure S8, Table S1). The dashed line guides the eye for 1:1 correlation. (C) Tafel plot of OER activity in $\mathrm{O}_{2}$-saturated $0.1 \mathrm{M} \mathrm{KOH}$, measured by cyclic voltammetry at $10 \mathrm{mV} / \mathrm{s}$ (averaged forward and back, line) and potentiostatic measurements (constant applied voltage, points). (D) OER activity at 1.53 $\mathrm{V}$ vs. RHE corresponds to the integrated charge from the Ru redox located at $\sim 1.35 \mathrm{~V}$ vs. RHE preceding the onset of OER (Figure S10). (100) and (110) data adapted from Ref. 6.

Figure 1

$144 \times 178 \mathrm{~mm}(300 \times 300 \mathrm{DPI})$ 
2

3

4

5

6

7

8

9

10

11

12

13

14

15

16

17

18

19

20

21

22

23

24

25

26

27

28

29

30

31

32

33

34

35

36

37

38

39

40

41

42

43

44

45

46

47

48

49

50

51

52

53

54

55

56

57

58

59

60

ACS Paragon Plus Environment 

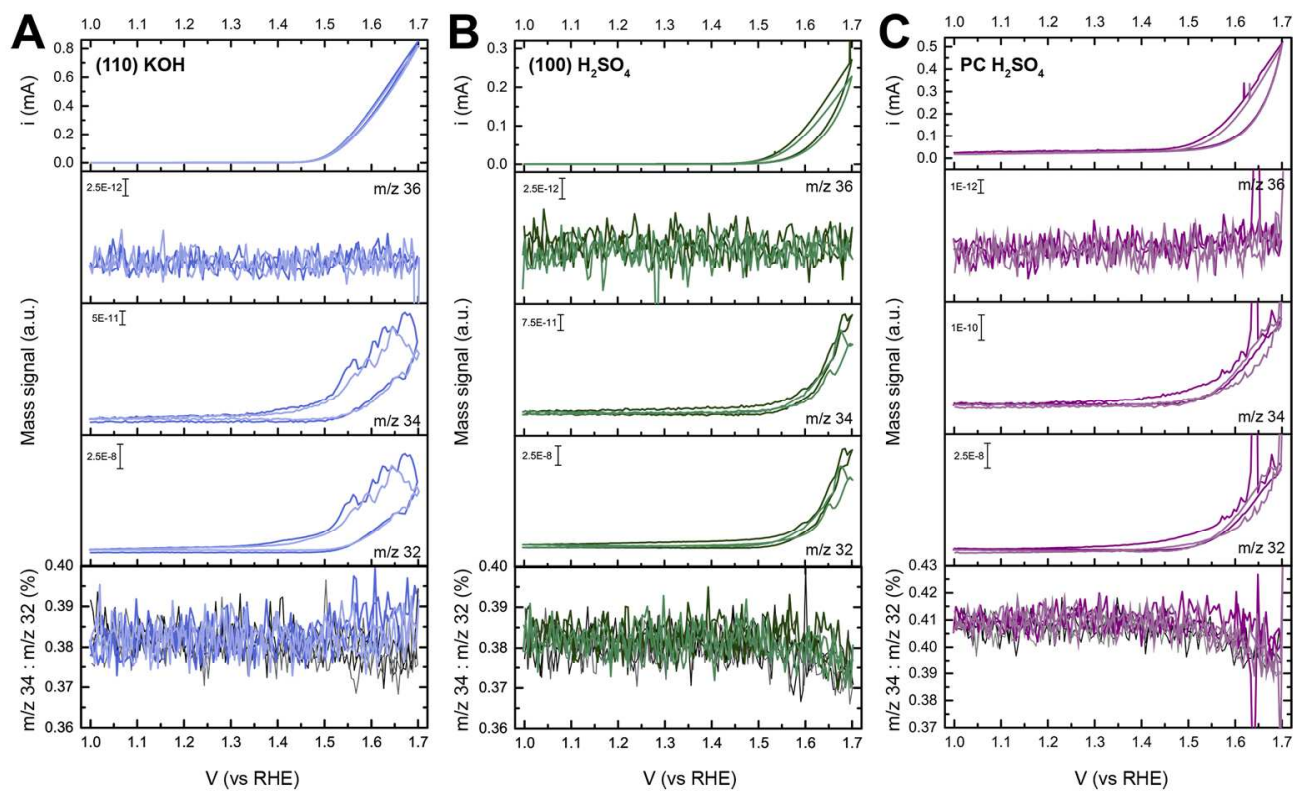

Figure 2. Online electrochemical mass spectrometry (OLEMS) measurements at $2 \mathrm{mV} / \mathrm{s}$ (see Experimental Methods for details). Shown is the current as a function of applied voltage, along with the mass signals collected in parallel for ${ }^{36} \mathrm{O}_{2},{ }^{34} \mathrm{O}_{2}\left({ }^{18} \mathrm{O}^{16} \mathrm{O}\right)$, and ${ }^{32} \mathrm{O}_{2}$ for a film galvanostatically polarized in $\mathrm{H}_{2}{ }^{18} \mathrm{O}$ to potentially 'label' it, measured in $\mathrm{H}_{2}{ }^{16} \mathrm{O}$ electrolyte (dark color first sweep, light color second). The ratio of the mass 34 to mass 32 signal, which is independent of applied potential and overtop the same ratio measured after aggressive polarization to remove any exchanged oxygen (black/gray sweeps), indicates any

${ }^{34} \mathrm{O}_{2}$ arises from background ${ }^{18} \mathrm{O}$. (A) (110)- $\mathrm{RuO}_{2}$ in $0.1 \mathrm{M} \mathrm{KOH}$, (B) (100)- $\mathrm{RuO}_{2}$ in $0.1 \mathrm{M} \mathrm{H}_{2} \mathrm{SO}_{4}$, and (C) sputter-deposited polyoriented polycrystalline (PC) $\mathrm{RuO}_{2}$ in $0.1 \mathrm{M} \mathrm{H}_{2} \mathrm{SO}_{4}$.

Figure 2

$177 \times 108 \mathrm{~mm}$ (300 x 300 DPI) 


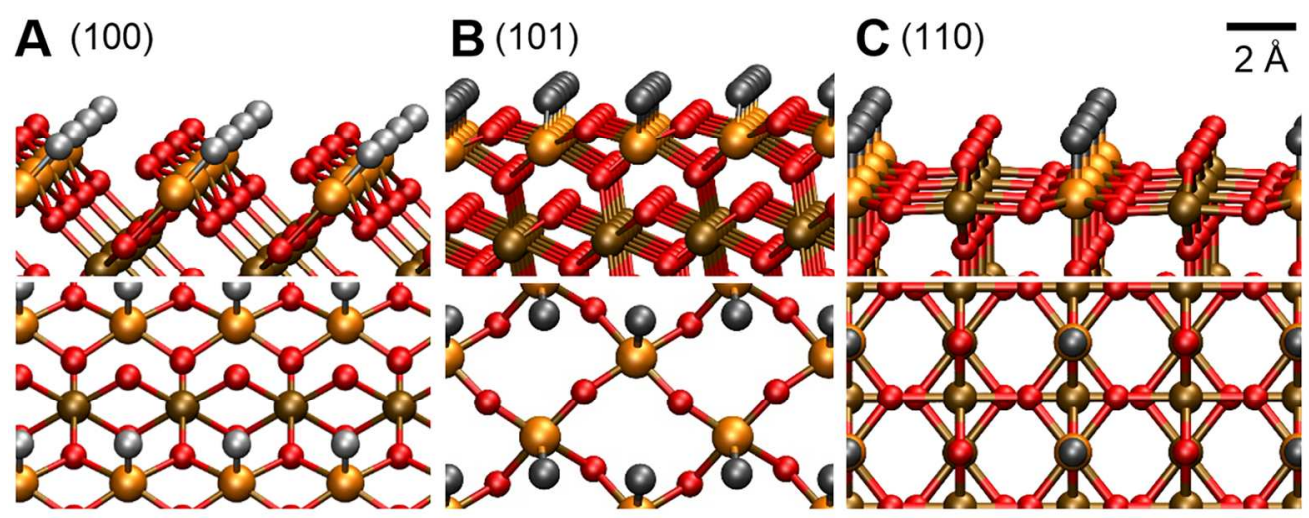

D (111)

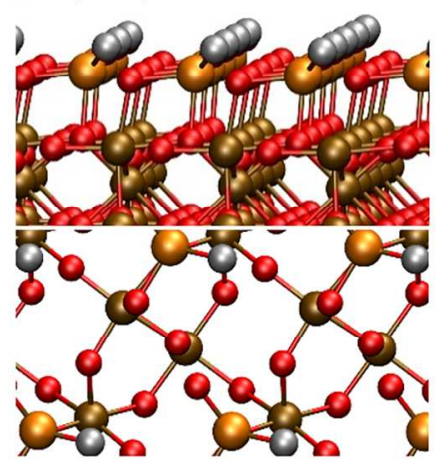

E

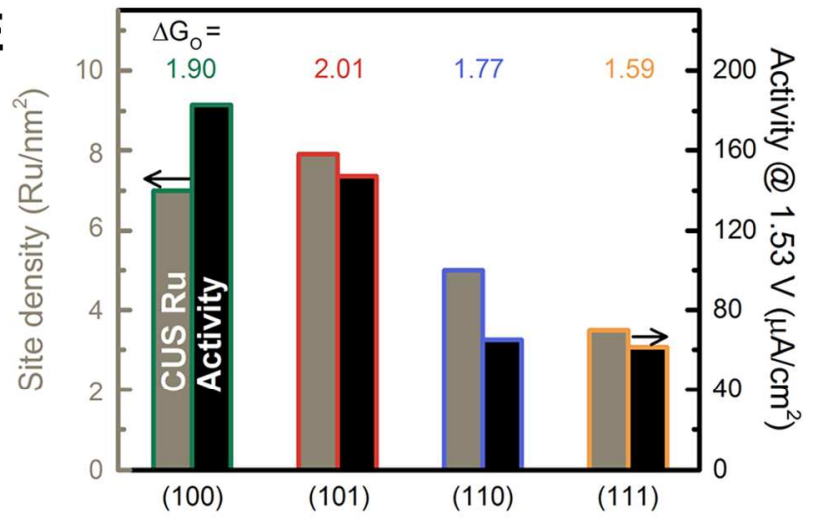

Figure 3. (A-D) $\mathrm{RuO}_{2}$ surfaces viewed from the side (top) and from above (bottom), where O-atoms are in red, inactive Ru atoms are in brown, and active undercoordinated sites are marked with a larger sphere in gold with silver atoms marking the location of the oxygen atom adsorbed on the active site. All images are on the same scale. (E) The OER activity at $1.53 \mathrm{~V}$ vs. RHE (right axis, black) scales with the number of active undercoordinated sites per area from DFT calculations (left axis, gray) for the four studied $\mathrm{RuO}_{2}$ orientations. A weaker Gibbs free energies per $\mathrm{O}$ atom $\left(\Delta \mathrm{G}_{\mathrm{O}}\right.$, in $\left.\mathrm{eV}\right)$ also corresponds to higher activity.

Figure 3

$165 \times 132 \mathrm{~mm}(300 \times 300 \mathrm{DPI})$ 